\title{
Capture of esophageal and breast cancer cells with polymeric microfluidic devices for CTC isolation
}

\author{
TAKASHI OHNAGA ${ }^{1}$, YUTAKA SHIMADA ${ }^{2}$, KOJI TAKATA $^{1}$, TSUTOMU OBATA ${ }^{1}$, TOMOYUKI OKUMURA ${ }^{3}$, \\ TAKUYA NAGATA ${ }^{3}$, HIROYUKI KISHI ${ }^{4}$, ATSUSHI MURAGUCHI ${ }^{4}$ and KAZUHIRO TSUKADA ${ }^{3}$ \\ ${ }^{1}$ Central Research Laboratories, Toyama Industrial Technology Center, Takaoka, Toyama 933-0981; \\ ${ }^{2}$ Department of Nanobio Drug Discovery, Graduate School of Pharmaceutical Sciences, Kyoto University, Kyoto 606-8501; \\ Departments of ${ }^{3}$ Surgery and Science and ${ }^{4}$ Immunology, Graduate School of Medicine \\ and Pharmaceutical Sciences, University of Toyama, Toyama 930-0194, Japan
}

Received March 12, 2015; Accepted December 22, 2015

DOI: $10.3892 / \mathrm{mco} .2016 .734$

\begin{abstract}
The present study evaluated the capture efficiency of esophageal and breast cancer cells with a modified 'polymeric circulating tumor cells (CTC)-chip' microfluidic device, which was developed for the isolation of circulating tumor cells. Esophageal cancer cell lines KYSE150, KYSE220 and KYSE510, and breast cancer cell lines MCF7, SKBR3 and MDA-MB-231 were used for evaluation. The capture efficiencies of the esophageal cancer cell lines in phosphate-buffered saline (PBS) were $\sim 0.9$, irrespective of epithelial cell adhesion molecule (EpCAM) expression, which was represented as the mean fluorescent intensity from 528 to 76 . In the breast cancer cell lines, efficient capture was observed for MCF7 and SKBR3 in PBS; however, a low value of $\sim 0.1$ was obtained for MDA-MB-231. Fluorescent imaging of immunolabeled cells revealed marginal EpCAM expression in MDA-MB-231. Using whole blood, no clogging occurred in the microstructure-modified CTC-chip and efficiency of capture was successfully evaluated. Capture efficiencies for KYSE220 and MCF7 in whole blood were $>0.7$, but were of either equal or lesser efficiency in comparison to PBS. Therefore, the modified CTC-chip appears useful for clinical application due to its cost, practicality of use, and efficient cancer cell capture.
\end{abstract}

\section{Introduction}

Numerous studies and reviews on circulating tumor cells (CTCs) have been found to be critically useful for clinical application in the diagnosis, therapy and research of cancer (1-14). CTCs are known to exist in the peripheral blood at an extremely

Correspondence to: Dr Takashi Ohnaga, Central Research Laboratories, Toyama Industrial Technology Center, 150 Futagami-cho, Takaoka, Toyama 933-0981, Japan

E-mail: ohnaga@itc.pref.toyama.jp

Key words: circulating tumor cell, microfluidic device, polymer, epithelial cell adhesion molecule, esophageal cancer cell, breast cancer cell low concentration and are difficult to isolate from the blood. Subsequently, a number of efforts have been made to develop devices and apparatus that are able to isolate CTCs. Our previous study designed and fabricated a novel CTC isolation device, a polymeric microfluidic device termed the 'CTC-chip', which is now commercially available (15). Although most microfluidic CTC isolation devices, including the conventional CTC-chip, are made of silicon or polydimethylsiloxane (16-19), these materials are not necessarily suitable for clinical applications in terms of cost, producibility and their material properties. The current polymeric devices are comprised of light-curable resins, which were formulated for easy production and clinical usability, and our previous study demonstrated that the device overcame practical usage issues faced by conventional chips. The device captures cancer cells by targeting the epithelial cell adhesion molecule (EpCAM) expressed on the surface of cancer cells using an immobilized anti-EpCAM antibody. As EpCAM expression is considered heterogeneous among CTCs from within a single patient and varies based on cancer type, it is important to estimate the influence of EpCAM expression on the efficiency of capture by the device. The present study evaluated the efficiency of capture by use of esophageal and breast cancer cell lines. The esophageal cancer cell lines were chosen as they exhibit different EpCAM expression levels measured by flow cytometry for the evaluation. As for the breast cancer cell lines, attention was focused not only on EpCAM expression but also on subtypes of breast cancer and used cell lines representing estrogen receptor positive/progesterone receptor positive $\left(\mathrm{ER}^{+} / \mathrm{PR}^{+}\right)$, human epidermal growth factor receptor 2 $\left(\mathrm{HER}^{+}\right)$and triple-negative breast cancers.

\section{Materials and methods}

Cancer cell lines and preparation of cell suspensions. Esophageal cancer cell lines KYSE150, KYSE220 and KYSE510 were kindly provided by Dr Yutaka Shimada (one of the authors of this manuscript), and breast cancer cell lines MCF7, SKBR3 and MDA-MB-231 were obtained from the American Type Culture Collection (Manassas, VA, USA). EpCAM expression levels were measured in the esophageal cancer lines using a BD FACSCanto flow cytometer (Becton-Dickinson, 

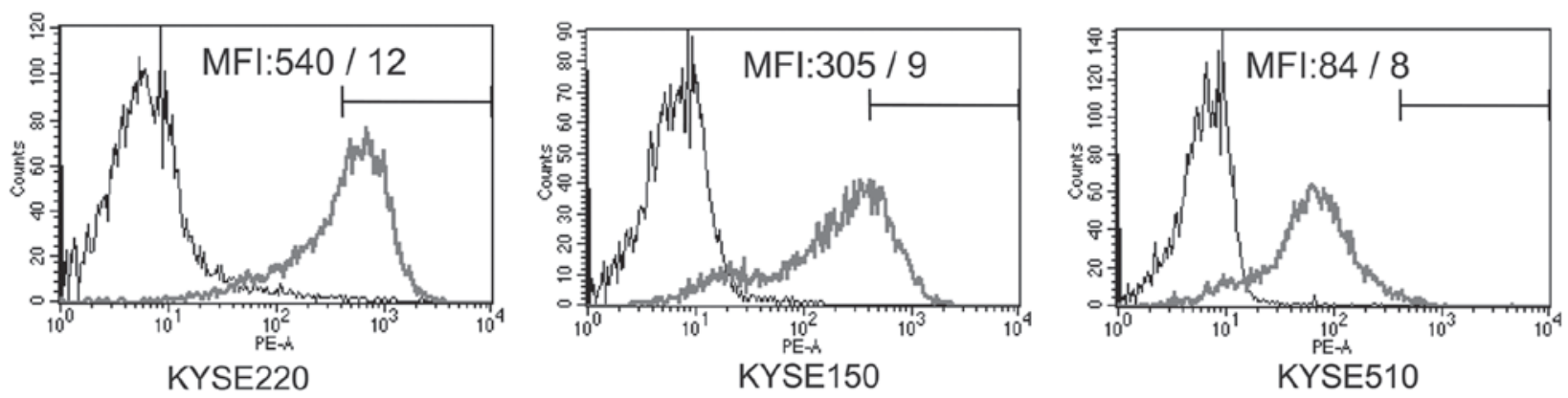

Figure 1. Epithelial cell adhesion molecule (EpCAM) expression levels of esophageal cancer cell lines measured by flow cytometry using mouse anti-EpCAM antibody and PE anti-mouse immunoglobulin G (IgG) antibody (gray lines), and control (PE anti-mouse IgG antibody only, black lines). The x-axis shows logarithmic fluorescence intensity. Mean fluorescence intensity (MFI) was calculated from the flow cytometry data.

San Jose, CA, USA), mouse anti-human EpCAM antibody (cat. no. sc-59906; Santa Cruz Biotechnology, Inc., Santa Cruz, CA, USA) and PE anti-mouse immunoglobulin $\mathrm{G}(\mathrm{IgG})$ antibody (cat. no. IM0551; Beckman Coulter, Brea, CA, USA).

For capture efficiency measurement, cancer cells were fluorescently labeled with CellTrace (Life Technologies, DriveRockville, MD, USA) and were either spiked into phosphate-buffered saline (PBS) containing 1\% bovine serum albumin or whole blood, which had been drawn from a healthy donor (following approval by the Ethics Comittee of the University of Toyama and after obtaining written informed concent) and stored in a vacuum blood collection tube containing ethylenediaminetetraacetic acid. The cell suspensions were prepared at concentrations between 100 and $400 \mathrm{cells} / \mathrm{ml}$.

Immunostaining of MDA-MB-231 and KYSE510 was performed using mouse anti-EpCAM and $\mathrm{Cy} 3$ goat anti-mouse IgG antibodies (cat. no. CLCC35010; Cedarlane, Hornby, ON, Canada). Cells cultured in 96-well microplates were fixed in $4 \%$ paraformaldehyde for $30 \mathrm{~min}$ and washed with PBS. Mouse anti-EpCAM antibody at a concentration of $20 \mu \mathrm{g} / \mathrm{ml}$ was applied to the cells for $2 \mathrm{~h}$ at room temperature. Cells were washed with PBS and stained with Cy3 goat anti-mouse IgG antibody at a concentration of $4 \mu \mathrm{g} / \mathrm{ml}$. Following a final wash with PBS, fluorescent microscopic images were captured using a digital camera.

Preparation of the polymeric CTC-chip. Production of the polymeric CTC-chip and antibody coating of the chip surface were carried out as described previously (15). The microstructure of the chip consisted chiefly of an array of two different types of microposts, modified from the previous design to prevent clogging by whole blood. The gap between microposts was enlarged to $200 \mu \mathrm{m}$ in the area around the chip inlet. Goat anti-mouse IgG antibody (cat. no. 1032-01; Southern Biotech, Birmingham, AL, USA) and mouse anti-human EpCAM antibody were used for chip coating.

Evaluation of cell capture efficiency by the polymeric CTC-chip. The polymeric CTC-chip was set in a holder and the efficiency of capture was evaluated using the method described previously with the cancer cell suspensions. Efficiency of capture was calculated by measuring the number of cells remaining on the chip following sample passage compared to the number of cells that passed through the chip inlet.

\section{Results}

EpCAM expression levels. EpCAM expression levels in the esophageal cancer cell lines were measured by flow cytometry and represented as relative mean fluorescent intensity (MFI), which changed between 528 and 76 for the different cell lines (Fig. 1). Capture efficiencies of the esophageal cancer cell lines in PBS were 0.9 irrespective of EpCAM expression levels (Fig. 2A). In the breast cancer cell lines, MCF7 and SKBR3 in PBS were efficiently captured, however a low value of $\sim 0.1$ was obtained for MDA-MB-231 (Fig. 2B). Fluorescent images of immunostained MDA-MB-231 and KYSE510 were captured and compared to roughly estimate EpCAM expression level of MDA-MB-231 (Fig. 3).

There was no clogging of the modified chip when using whole blood (Fig. 4) and the efficiency of cell capture was successfully evaluated. Capture efficiencies for KYSE220 and MCF7 in whole blood were $>0.7$, but were of either equal or lesser efficiency in comparison to PBS (Fig. 2C).

\section{Discussion}

In the present study, the polymeric CTC-chip efficiently captured esophageal and breast cancer cells except for MDA-MB-231 in PBS. All the esophageal cancer cells used exhibited an MFI between 528 and 76, indicating EpCAM expression, with the lowest EpCAM-expressing cell line, KYSE510, still efficiently captured as shown by the bright image of the stained cells in Fig. 3B. The breast cancer lines MCF7 and SKBR3 have been previously shown to express sufficient EpCAM to allow efficient capture by other microfluidic devices (19-21), which was in accordance with the present results. Capture efficiency of SKBR3 by conventional CTC-chip was lower than the polymeric chip. Capture efficiency of MDA-MB-231 was extremely low and appeared reasonable due to marginal EpCAM expression, as shown in Fig. 3A. Previous studies have confirmed MDA-MB-231 to have extremely low EpCAM expression (22-25). However, the capture efficiency obtained for MDA-MBA-231 suggests that the extremely low level of EpCAM still had a role in capture due to obtaining a capture efficiency of only 0.02 when coating the polymeric CTC-chip with only anti-mouse $\mathrm{IgG}$ antibody. Low capture efficiencies of MDA-MB-231 and other cancer cell lines exhibiting downregulation of EpCAM, often caused by epithelial-mesenchymal transition (EMT), have also been observed in PBS or whole 
A

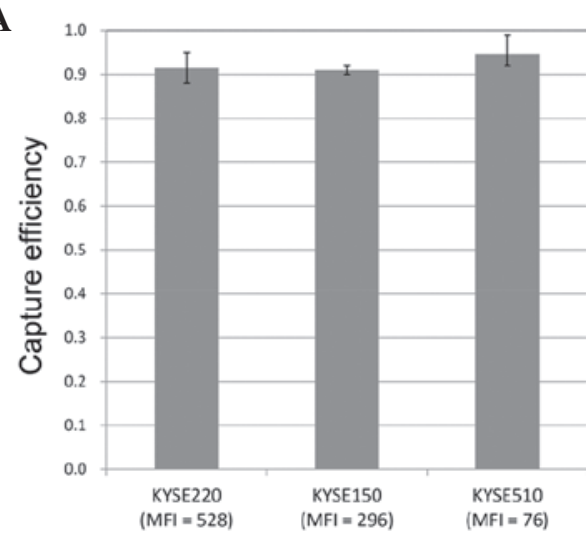

B

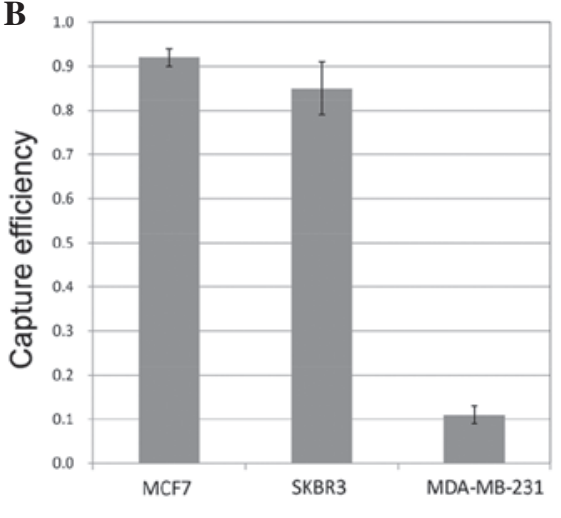

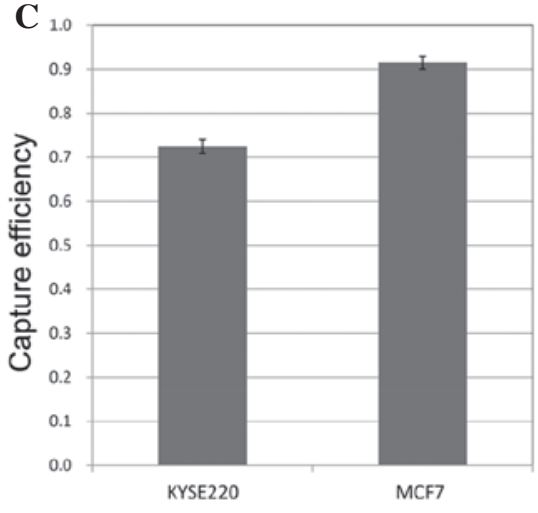

Figure 2. Capture efficiencies of the cancer cell lines by the polymeric circulating tumor cells-chip in phosphate-buffered saline (PBS) or whole blood. (A) Esophageal cancer cell lines in PBS. (B) Breast cancer cell lines in PBS. (C) KYSE220 and MCF7 in whole blood.

A

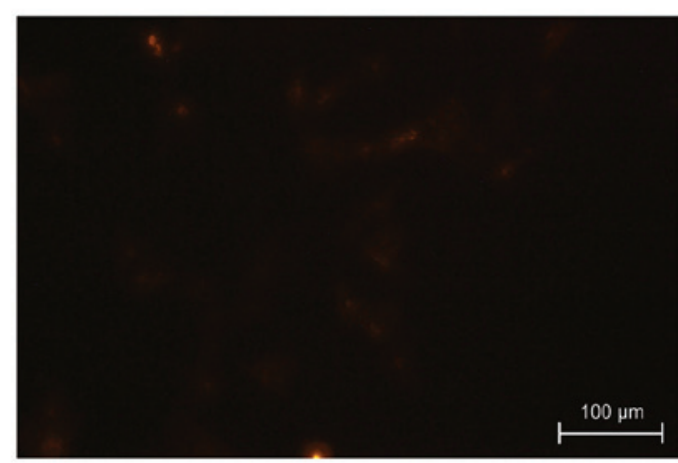

B

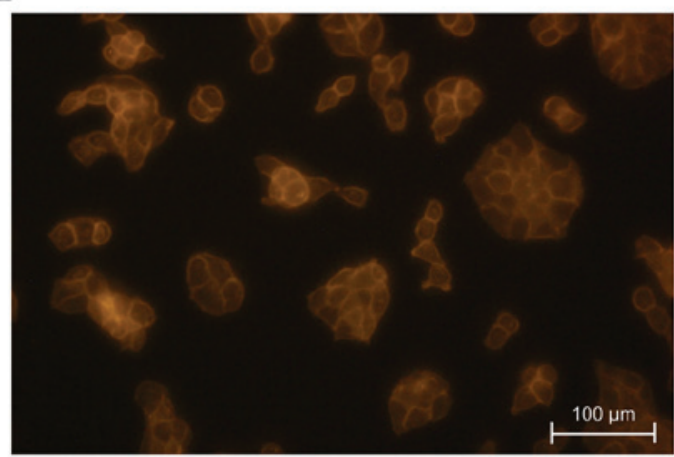

Figure 3. Fluorescent images of immunostained cells using mouse anti-epithelial cell adhesion molecule (EpCAM) antibody and Cy3 goat anti-mouse immunoglobulin G antibody. (A) MDA-MB-231. (B) KYSE510.

A

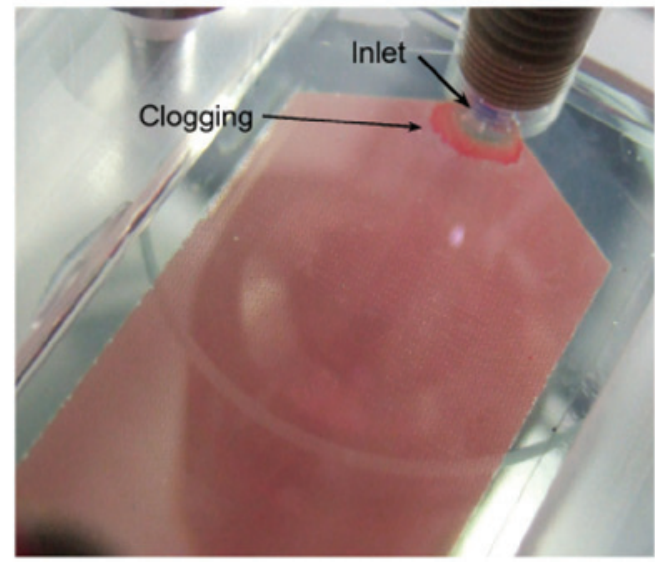

B

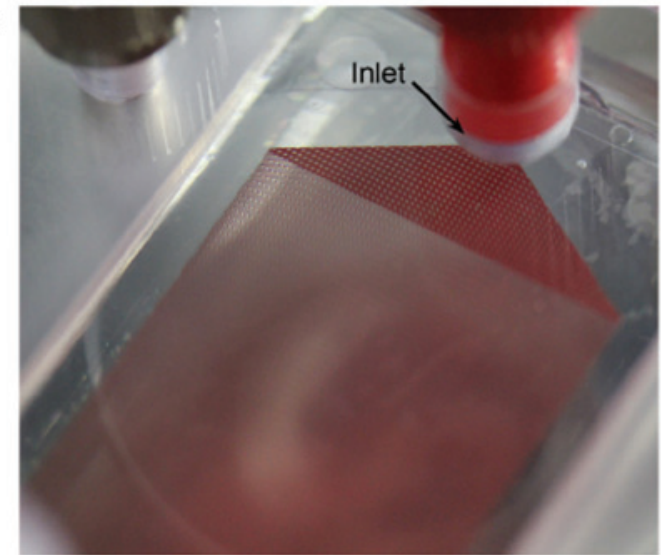

Figure 4. Images of whole blood passing through the polymeric circulating tumor cells-chip. (A) Previous chip clogged with whole blood. (B) Modified chip with a larger gap between microposts and no clogging.

blood using other microfluidic devices or methods utilizing antibody-based capture of EpCAM $(20,21,23)$. Recently, other microfluidic devices have targeted cell surface antigens, such as prostate-specific membrane antigen (PSMA), HER2 and epidermal growth factor receptor (EGFR) by incorporating antibodies against these antigens, and have successfully isolated CTCs from the blood of cancer patients $(20,26,27)$. MDA-MB-231 cells have been reported to be captured efficiently by a microfluidic device using anti-EGFR antibody, and this modification may be effective in the polymeric CTC-chip and easy to apply. Various antibodies are able to be simply attached to the chip surface by initial anti-IgG antibody bonding. However, these cell surface antigens are only able to target a narrow range of cancer type, such as PSMA to prostate cancer, and are known to change expression by EMT; therefore, universal targets for efficient capture of a wide range of CTCs 
are still required. Much challenging work is still required to find ideal markers for the identification of cancer cells, which may subsequently be used as targets for capture (6).

Although whole blood samples caused the polymeric CTC-chip to clog in our previous study, whole blood was able to pass through the modified chip to successfully evaluate the efficiency of cell capture. This change was due to enlargement of the gap between microposts in the modified chip. Shear stress at the interface between the microposts and whole blood sample decreased by gap enlargement and local instances of blood coagulation appeared to be reduced, resulting in reduction of clogging.

As determined in the present study, capture efficiency may be generally lower in the whole blood compared to PBS. However, further studies must be carried out to clarify this issue, due to efficiency being influenced by numerous factors, such as viscosity, adsorption of cells and proteins, leading to complications.

\section{Acknowledgements}

The present study was supported by the Grant-in-Aid for Scientific Research (no. 25350582).

\section{References}

1. Sheng W, Ogunwobi OO, Chen T, Zhang J, George TJ, Liu C and Fan ZH: Capture, release and culture of circulating tumor cells from pancreatic cancer patients using an enhanced mixing chip. Lab Chip 14: 89-98, 2014.

2. Babayan A, Hannemann J, Spötter J, Müller V, Pantel K and Joosse SA: Heterogeneity of estrogen receptor expression in circulating tumor cells from metastatic breast cancer patients. PLoS One 8: e75038, 2013.

3. Liu Y, Liu Q, Wang T, Bian L, Zhang S, Hu H, Li S, Hu Z, Wu S, Liu B, et al: Circulating tumor cells in HER2-positive metastatic breast cancer patients: A valuable prognostic and predictive biomarker. BMC Cancer 13: 202, 2013.

4. Onstenk W, Gratama JW, Foekens JA and Sleijfer S: Towards a personalized breast cancer treatment approach guided by circulating tumor cell (CTC) characteristics. Cancer Treat Rev 39: 691-700, 2013.

5. Torino F, Bonmassar E, Bonmassar L, De Vecchis L, Barnabei A, Zuppi C, Capoluongo E and Aquino A: Circulating tumor cells in colorectal cancer patients. Cancer Treat Rev 39: 759-772, 2013.

6. Yokobori T, Iinuma H, Shimamura T, Imoto S, Sugimachi K, Ishii H, Iwatsuki M, Ota D, Ohkuma M, Iwaya T, et al: Plastin3 is a novel marker for circulating tumor cells undergoing the epithelial-mesenchymal transition and is associated with colorectal cancer prognosis. Cancer Res 73: 2059-2069, 2013.

7. Franken B, de Groot MR, Mastboom WJB, Vermes I, van der Palen J, Tibbe AGJ and Terstappen LWMM: Circulating tumor cells, disease recurrence and survival in newly diagnosed breast cancer. Breast Cancer Res 14: R133, 2012.

8. Hou JM, Krebs MG, Lancashire L, Sloane R, Backen A, Swain RK, Priest LJC, Greystoke A, Zhou C, Morris K, et al: Clinical significance and molecular characteristics of circulating tumor cells and circulating tumor microemboli in patients with small-cell lung cancer. J Clin Oncol 30: 525-532, 2012.

9. Matsusaka S, Suenaga M, Mishima Y, Kuniyoshi R, Takagi K, Terui Y, Mizunuma N and Hatake K: Circulating tumor cells as a surrogate marker for determining response to chemotherapy in Japanese patients with metastatic colorectal cancer. Cancer Sci 102: 1188-1192, 2011.

10. Park Y, Kitahara T, Urita T, Yoshida Y and Kato R: Expected clinical applications of circulating tumor cells in breast cancer. World J Clin Oncol 2: 303-310, 2011.

11. Stott SL, Lee RJ, Nagrath S, Yu M, Miyamoto DT, Ulkus L, Inserra EJ, Ulman M, Springer S, Nakamura Z, et al: Isolation and characterization of circulating tumor cells from patients with localized and metastatic prostate cancer. Sci Transl Med 2: 25ra23, 2010.
12. Okegawa T, Nutahara $K$ and Higashihara E: Association of circulating tumor cells with tumor-related methylated DNA in patients with hormone-refractory prostate cancer. Int J Urol 17: 466-475, 2010.

13. Okegawa T, Nutahara K and Higashihara E: Prognostic significance of circulating tumor cells in patients with hormone refractory prostate cancer. J Urol 181: 1091-1097, 2009.

14. Wülfing P, Borchard J, Buerger H, Heidl S, Zänker KS, Kiesel L and Brandt B: HER2-positive circulating tumor cells indicate poor clinical outcome in stage I to III breast cancer patients. Clin Cancer Res 12: 1715-1720, 2006.

15. Ohnaga T, Shimada Y, Moriyama M, Kishi H, Obata T, Takata K, Okumura T, Nagata T, Muraguchi A and Tsukada K: Polymeric microfluidic devices exhibiting sufficient capture of cancer cell line for isolation of circulating tumor cells. Biomed Microdevices 15: 611-616, 2013.

16. Nora Dickson M, Tsinberg P, Tang Z, Bischoff FZ, Wilson T and Leonard EF: Efficient capture of circulating tumor cells with a novel immunocytochemical microfluidic device. Biomicrofluidics 5: 34119-3411915, 2011.

17. Stott SL, Hsu CH, Tsukrov DI, Yu M, Miyamoto DT, Waltman BA, Rothenberg SM, Shah AM, Smas ME, Korir GK, et al: Isolation of circulating tumor cells using a microvortex-generating herringbone-chip. Proc Natl Acad Sci USA 107: 18392-18397, 2010.

18. Gleghorn JP, Pratt ED, Denning D, Liu H, Bander NH, Tagawa ST, Nanus DM, Giannakakou PA and Kirby BJ: Capture of circulating tumor cells from whole blood of prostate cancer patients using geometrically enhanced differential immunocapture (GEDI) and a prostate-specific antibody. Lab Chip 10: 27-29, 2010.

19. Nagrath S, Sequist LV, Maheswaran S, Bell DW, Irimia D, Ulkus L, Smith MR, Kwak EL, Digumarthy S, Muzikansky A, et al: Isolation of rare circulating tumour cells in cancer patients by microchip technology. Nature 450: 1235-1239, 2007.

20. Yu M, Bardia A, Wittner BS, Stott SL, Smas ME, Ting DT, Isakoff SJ, Ciciliano JC, Wells MN, Shah AM, et al: Circulating breast tumor cells exhibit dynamic changes in epithelial and mesenchymal composition. Science 339: 580-584, 2013.

21. Punnoose EA, Atwal SK, Spoerke JM, Savage H, Pandita A Yeh RF, Pirzkall A, Fine BM, Amler LC, Chen DS, et al: Molecular biomarker analyses using circulating tumor cells. PLoS One 5: e12517, 2010.

22. Martowicz A, Spizzo G, Gastl G and Untergasser G: Phenotype-dependent effects of EpCAM expression on growth and invasion of human breast cancer cell lines. BMC Cancer 12: 501, 2012.

23. Pecot CV, Bischoff FZ, Mayer JA, Wong KL, Pham T, Bottsford-Miller J, Stone RL, Lin YG, Jaladurgam P, Roh JW, et al: A novel platform for detection of CK+ and CK- CTCs. Cancer Discov 1: 580-586, 2011.

24. Sieuwerts AM, Kraan J, Bolt J, van der Spoel P, Elstrodt F, Schutte M, Martens JWM, Gratama JW, Sleijfer S and Foekens JA: Anti-epithelial cell adhesion molecule antibodies and the detection of circulating normal-like breast tumor cells. J Natl Cancer Inst 101: 61-66, 2009.

25. Prang N, Preithner S, Brischwein K, Göster P, Wöppel A, Müller J, Steiger C, Peters M, Baeuerle PA and da Silva AJ: Cellular and complement-dependent cytotoxicity of Ep-CAM-specific monoclonal antibody MT201 against breast cancer cell lines. Br J Cancer 92: 342-349, 2005.

26. Galletti G, Sung MS, Vahdat LT, Shah MA, Santana SM, Altavilla G, Kirby BJ and Giannakakou P: Isolation of breast cancer and gastric cancer circulating tumor cells by use of an anti HER2-based microfluidic device. Lab Chip 14: 147-156, 2014.

27. Kirby BJ, Jodari M, Loftus MS, Gakhar G, Pratt ED, Chanel-Vos C, Gleghorn JP, Santana SM, Liu H, Smith JP, et al: Functional characterization of circulating tumor cells with a prostate-cancer-specific microfluidic device. PLoS One 7: e35976, 2012. 